\title{
Isolated cotton-wool spots of unknown etiology: management and sequential spectral domain optical coherence tomography documentation
}

This article was published in the following Dove Press journal:

Clinical Ophthalmology

3 October 2011

Number of times this article has been viewed

\author{
Antonis loannides \\ Nikolaos D Georgakarakos ${ }^{2}$ \\ Ibrahim Elaroud ${ }^{3}$ \\ Petros Andreou' \\ 'Ophthalmology Department, \\ Mid-Essex Hospitals NHS \\ Trust, Chelmsford, ${ }^{2}$ Institute of \\ Ophthalmology, University College \\ London, London, ${ }^{3}$ Ophthalmology \\ Department, Mid-Yorkshire Hospitals \\ NHS Trust, Yorkshire, UK
}

\begin{abstract}
Cotton-wool spots (CWSs) are common retinal manifestations of many diseases including diabetes mellitus, systemic hypertension, and acquired immunodeficiency syndrome. Clinically they appear as whitish, fluffy patches on the retina and eventually fade with time. In this study, spectral domain optical coherence tomography (SD-OCT) with mapping was used to demonstrate in vivo the characteristics of an isolated CWS in a 59-year-old patient as well as its appearance immediately after ophthalmoscopic resolution. Presented here is the work-up and management of this clinical problem for the ophthalmologist. The authors propose that SD-OCT could be a valuable research tool in characterizing and following the dynamic CWS changes at individual retinal layer level, with potential clinical applications as a screening or diagnostic tool in CWS-related diseases.
\end{abstract}

Keywords: SD-OCT, spectral domain optical coherence tomography, retinal lesion

\section{Introduction}

Cotton-wool spots (CWSs) are retinal lesions, most commonly seen as manifestations of diabetes mellitus and systemic hypertension. They are also associated with a number of other etiologies including ischemic, embolic, connective tissue, neoplastic, and infectious, ${ }^{1,2}$ but occasionally no underlying cause can be identified. ${ }^{2}$

CWSs are thought to represent axoplasmic debris at the level of retinal ganglion cell axons resulting from axoplasmic flow interruption due to vascular or mechanical causes. ${ }^{3}$ Ophthalmoscopically, CWSs appear as whitish, fluffy retinal patches that eventually fade with time. ${ }^{4}$ Described in this paper is the use of spectral domain optical coherence tomography (SD-OCT) to document the progression of an isolated cotton-wool spot, from presentation to fundoscopic resolution.

\section{Case report}

A 59-year-old chemist presented to the ophthalmology department with a 3-day history of acute onset, painless reduction of the paracentral vision of his left eye. He used spectacles for reading and was previously fit and well with no history of ophthalmic or systemic disease. He wasn't taking any medication, had never smoked, and there was no family history of note.

His uncorrected visual acuities were 20/16 right and 20/20 left. Ocular examination showed an isolated CWS located between his left optic disc and macula (Figure 1A) but no other pathology. His blood pressure was $138 / 82 \mathrm{mmHg}$ and systemic examination was unremarkable.
Correspondence: Antonis loannides

Ophthalmology Department, Mid-Essex Hospitals NHS Trust,

Court Road, Chelmsford, CMI 7ET, UK

Tel +44776588 8750

Fax +448448220002

Email antonis@antonis.org 


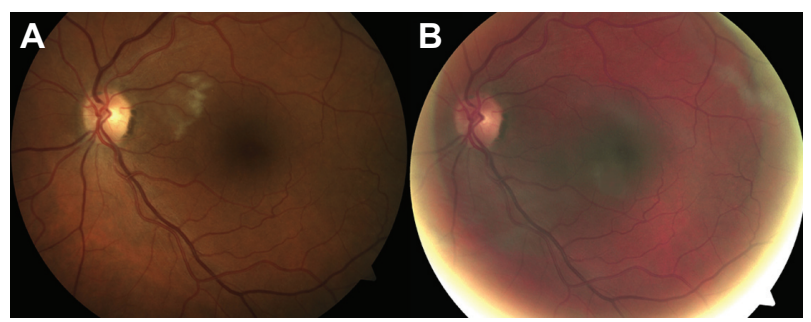

Figure I Left fundus photographs: at presentation showing an isolated cotton-wool spot (A); and 9 weeks later showing resolution (B).

A full hematological work-up was performed that included fasting glucose, complete blood count, urea, electrolytes and calcium, lipid profile, inflammatory markers, coagulation, connective tissue disease markers, human immunodeficiency virus (HIV), and serum protein electrophoresis. In addition, 24-hour urine was collected for quantification. Results were negative. Carotid Doppler ultrasound and echocardiography were also unremarkable.

The patient's fundus fluorescein angiogram images at presentation were consistent with the ophthalmoscopic findings and did not reveal any evidence of other abnormalities than the isolated CWS in his left retina.

SD-OCT with Cirrus HD-OCT (Carl Zeiss Meditec Inc, Dublin, CA), also performed at presentation, showed marked retinal thickening corresponding to the area of the CWS (Figure 2A). The thickening was confined to the level of the retinal nerve fiber layer (Figure 3A).

The patient was reviewed 9 weeks later. He reported that the vision in his left eye had returned to normal. Fundoscopically, there was resolution of the CWS (Figure 1B) without any intervention. His blood pressure was still within normal limits at $135 / 79 \mathrm{mmHg}$. Based on the whole clinical picture, the authors of this paper felt that further exhaustive investigations to establish an underlying cause for the CWS were inappropriate, and a diagnosis of isolated cotton-wool spot of unknown etiology was made.

At 9 weeks from presentation, the area of the resolved CWS was scanned again with the Cirrus HD-OCT using software (version 4.0.1.3) that allowed real-time automatic
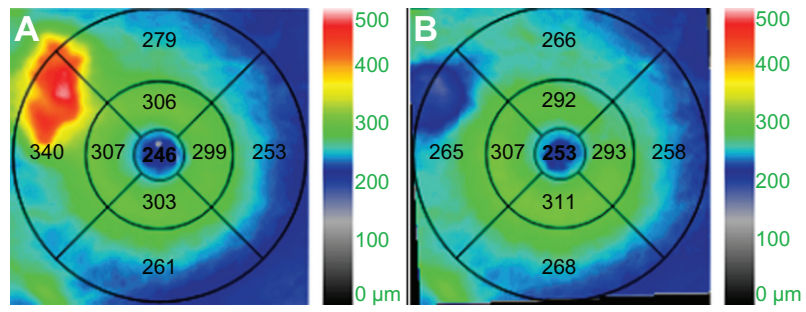

Figure 2 Cirrus HD-OCT (Carl Zeiss Meditec Inc, Dublin, CA) retinal thickness maps: at presentation showing thickening (glowing red) of an area corresponding to the cotton-wool spot $(\mathbf{A})$; and 9 weeks later showing focal thinning (B).

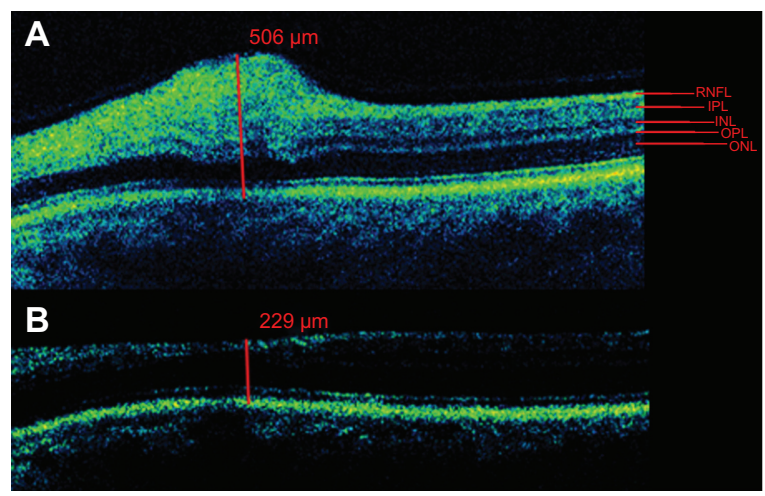

Figure 3 Cirrus HD-OCT (Carl Zeiss Meditec Inc, Dublin, CA) scans across the area of the cotton-wool spot: at presentation showing a maximum overall retinal thickness of $506 \mu \mathrm{m}$ with focal thickening of the retinal nerve fiber layer (A); and 9 weeks later showing a corresponding overall retinal thickness of $229 \mu \mathrm{m}$ (B). Abbreviations: RNFL, retinal nerve fibre layer; INL, inner nerve layer; IPL, inner plexiform layer; ONL, outer nuclear layer; OPL, outer plexiform layer.

registration for thickness change analysis as well as side-byside visual inspection. There was significant intraretinal thinning at the area of the lesion compared with adjacent healthy retina, evident on the retinal thickness map (Figure 2B) as well as the longitudinal image (Figure 3B), although it was not clear which individual retinal layer levels were affected.

\section{Discussion}

CWSs are useful fundoscopic signs for grading hypertensive retinopathy ${ }^{5}$ and diabetic retinopathy. ${ }^{6,7}$ They signal a declining CD4 count in HIV disease ${ }^{8}$ and are commonly seen in the course of central and branch retinal vein occlusions. ${ }^{9,10}$ CWSs can be a presenting sign of multiple myeloma ${ }^{11}$ and post-radiation retinopathy ${ }^{12}$ and are associated with a wide spectrum of diseases including cardiac valvular disease, carotid artery obstruction, dermatomyositis, systemic lupus erythematosus, polyarteritis nodosa, leukemia, metastatic carcinoma, Purtscher retinopathy, and giant cell arteritis. ${ }^{2}$

Patients may experience relative or absolute scotomas corresponding to the areas of CWSs. ${ }^{13}$ Following ophthalmoscopic resolution, visual function does not usually recover, although recovery was reported by the patient in this study and has also been documented by other authors. ${ }^{14,15}$ The mechanism of visual recovery is unknown, but a plausible explanation might be survival of enough retinal ganglion cell axons during the initial "assault" by the axoplasmic debris. If the number of surviving retinal ganglion cells is above a certain threshold, signal transmission - or at least part of it - is reestablished following resolution of the axoplasmic debris.

In recent years, SD-OCT has been established as a powerful weapon in the armamentarium of the retina specialist. But until now, there has been limited research on the SD-OCT 
characteristics of ophthalmoscopically visible CWSs and practically no clinical applications. Using SD-OCT as well as software mapping to more accurately identify, scan, and measure the same anatomical area of the retina in the patient, the structural changes associated with a CWS episode were able to be demonstrated and characterized in vivo.

Firstly, in the acute phase, 3 days from the onset of symptoms, there was marked thickening of the retina (Figure 2A) confined to the retinal nerve fiber layer with no apparent thickness change in the other layers (Figure 3A). This is consistent with the theory of accumulation of axoplasmic debris at the level of retinal ganglion cell axons ${ }^{16}$ that is visible ophthalmoscopically as a CWS.

Secondly, following ophthalmoscopic resolution at 9 weeks, there was overall retinal thinning at the area of the lesion compared with adjacent healthy retina, evident on the retinal thickness map (Figure 2B) as well as the longitudinal image (Figure 3B). Although not all individual retinal layers were distinguishable, a previous case series ${ }^{17}$ has showed marked ganglion cell layer thinning and moderate retinal nerve fiber layer, inner nuclear layer, inner plexiform layer, outer plexiform layer thinning with moderate outer nuclear layer thickening following resolution (2-11 years) of CWS in HIV disease. This is the first OCT report demonstrating retinal thinning, just 9 weeks from presentation of a CWS.

\section{Conclusion}

SD-OCT imaging has provided a new insight into the dynamic changes of the diseased retina. This image study suggests that SD-OCT can be a valuable research tool in following, in vivo, the anatomical and histological changes at individual retinal layer level of CWSs acutely and after apparent resolution.

As the use of retinal OCT imaging in ophthalmology clinics becomes more common and resolution of images improves further, it is possible that high-resolution OCT could also prove to be a useful screening or diagnostic tool in systemic disease for establishing areas of resolved CWS, in fundoscopically healthy looking retinas.

Additionally it can be used to determine the stage of disease progression or disease regression depending on the nature of retinal vascular pathology and severity in conjunction with the clinical symptomatology. The advances in high-resolution OCT technology allow histological analysis of the neurosensory retina in health and disease with multiple clinical applications.

\section{Disclosure}

The authors declare no conflicts of interest in this work.

\section{References}

1. Mansour AM, Jampol LM, Logani S, Read J, Henderly D. Cotton-wool spots in acquired immunodeficiency syndrome compared with diabetes mellitus, systemic hypertension, and central retinal vein occlusion. Arch Ophthalmol. 1988;106(8):1074-1077.

2. Brown GC, Brown MM, Hiller T, Fischer D, Benson WE, Magargal LE. Cotton-wool spots. Retina. 1985;5(4):206-214.

3. McLeod D, Marshall J, Kohner EM, Bird AC. The role of axoplasmic transport in the pathogenesis of retinal cotton-wool spots. $\mathrm{Br} J$ Ophthalmol. 1977:61(3):177-191.

4. Green WR. Retina. In: Spencer WH, editor. Ophthalmic Pathology. 4th ed. Philadelphia: Saunders; 1996:727.

5. Wong TY, Mitchell P. Hypertensive retinopathy. N Engl J Med. 2004; 351:2310-2317.

6. Niemeijer M, Van Ginneken B, Russell SR, Suttorp-Schulten MSA, Abràmoff $\mathrm{MD}$. Automated detection and differentiation of drusen, exudates, and cotton-wool spots in digital color fundus photographs for diabetic retinopathy diagnosis. Invest Ophthalmol Vis Sci. 2007;48(5):2260-2267.

7. Davis D, Fisher MR, Gangnon RE, et al. Risk factors for high-risk proliferative diabetic retinopathy and severe visual loss: Early Treatment Diabetic Retinopathy Study. Invest Ophthalmol Vis Sci. 1998;39(2):233-252.

8. Freeman WR, McCutchan AJ, Arevalo JF, et al; and HNRC Group. The relationship between AIDS retinal cotton wool spots and neuropsychological impairment in HIV-positive individuals in the pre-highly active antiretroviral therapy era. Ocul Immunol Inflamm. 2004;12(1):25-33.

9. Wolter JR. Retinal pathology after central retinal vein occlusion. $B r J$ Ophthalmol. 1979;45(10):683-694.

10. Hockley JD, Tripathi RC, Ashton N. Experimental retinal branch vein occlusion in rhesus monkeys. III. Histopathological and electron microscopical studies. Br J Ophthalmol. 1979;63(6):393-411.

11. Shami MJ, Uy RN. Isolated cotton-wool spots in a 67-year-old woman. Surv Ophthalmol. 1996;40(5):413-415.

12. Hayreh SS. Post-radiation retinopathy. A fluorescence fundus angiographic study. Br J Ophthalmol. 1970;54(11):705-714.

13. Bek T, Lund-Andersen $H$. Cotton-wool spots and retinal light sensitivity in diabetic retinopathy. Br J Ophthalmol. 1991;75(1):13-17.

14. King-Smith PE, Vingrys AJ, Benes SC, Grigsby SS, Billock VA. Detection of light and dark, red and green, blue and yellow. In: Kulikowski JJ, Dickinson CM, Murray IJ, editors. Seeing Contour and Colors. Oxford: Pergamon Press; 1989:381-391.

15. King-Smith PE, Vingrys AJ, Benes SC. Visual thresholds measured with color video monitors. Color Res Appl. 1987;12(2):73-80.

16. McLeod D. Why cotton wool spots should not be regarded as retinal nerve fibre layer infarcts. Br J Ophthalmol. 2005;89:229-237.

17. Gomez ML, Mojana F, Bartsch DU, Freeman WR. Imaging of longterm retinal damage after resolved cotton wool spots. Ophthalmology. 2009; 116(12):2407-2414.
Clinical Ophthalmology

\section{Publish your work in this journal}

Clinical Ophthalmology is an international, peer-reviewed journal covering all subspecialties within ophthalmology. Key topics include: Optometry; Visual science; Pharmacology and drug therapy in eye diseases; Basic Sciences; Primary and Secondary eye care; Patient Safety and Quality of Care Improvements. This journal is indexed on

\section{Dovepress}

PubMed Central and CAS, and is the official journal of The Society of Clinical Ophthalmology (SCO). The manuscript management system is completely online and includes a very quick and fair peer-review system, which is all easy to use. Visit http://www.dovepress.com/ testimonials.php to read real quotes from published authors. 